\title{
Rethinking the tendering frameworks of construction con- tractors in the context of a soft systems methodology approach
}

(C) The Author(s) 2018. Published by Higher Education Press. This is an open access article under the CC BY license (http:// creativecommons.org/licenses/by/4.0)

\begin{abstract}
Limited research has been conducted on the internal tendering procedures (ITP) of construction contractors because of the commercially sensitive and confidential nature of the subject matter. This limitation explains the reluctance of contractors to undergo interviews. Existing research (outside bid/no-bid and margin decision factor identification and subsequent decision modeling development) only begins to provide insights into key tendering stages, particularly around risk assessments and corporate review processes. Early research suggested one to three review stages. However, when considering the whole work procurement process from prospect identification to contract execution, five to seven series of reviews can be arguably applied by some contractors, wherein some reviews stepped through several layers of internal senior management. Tendering processes were presented as flowchart models that traditionally follow "hard" system (rectangular shapes and straight line arrows) steps, which suggest that a precise process also leads to precise results. However, given that contractors do not win every tender they submit, the process is less precise than that suggested in rigidly structured flowcharts. Twenty-five detailed semi-structured interviews were held with purposely selected high-profile publicly and privately owned construction companies in Australia with significantly varied turnovers. Analyses show that contractors are concerned about the negative effects of increasing corporate governance demands, with many stating that people involved are the most critical element to tendering success. A new way of presenting the ITP of contractors is assessed using a soft systems methodology
\end{abstract}

Received February 27, 2018; accepted May 25, 2018

Stephen URQUHART ( $₫)$, Andrew WHYTE

School of Civil and Mechanical Engineering, Curtin University, Kent Street, Bentley, Perth, Western Australia 6102, Australia

E-mail: stephen.urquhart@postgrad.curtin.edu.au
(SSM) approach. SSM offers an alternative way of considering human interaction challenges within the ITP of contractors, which needs to be tested with the industry. The format graphics of SSM guidelines are presented as a way of offering contractors a different approach, which may assist individuals who are looking to re-structure their tendering activities in a more humanistic and less rigid procedural approach.

Keywords contractor, corporate governance, humanistic, risk, soft systems methodology, tendering procedures

\section{Introduction}

The internal tendering procedures (ITP) of construction contractors are rarely examined because of the commercially sensitive nature of this part of their businesses (Laryea, 2013). ITPs are usually part of a contractor's quality management system (QMS) that is commonly certified by ISO 9001 (SAL, 2008, 2016) or similar international standard-setting bodies. However, following rigid written inputs and review steps cannot guarantee consistently repeatable tender "win" rates or subsequent project profits arising from those tender wins, as would be expected from production-type procedures such as in steel manufacturing or asphalt placement. Hence, the question arises as to whether contractors' ITPs could be developed and presented in a less regimented and formulaic structure. The discussion below addresses this question.

A series of semi-structured interviews were undertaken with a range of publicly and privately owned construction companies as part of a wider study into the effectiveness and efficiency of contractors' ITP. These interviews were conducted to gain a better understanding of the potentially negative impact of increasing corporate governance 
requirements on such procedures. A publicly owned company is described as a company or a subsidiary of a company listed in a stock exchange, such as the Australian Securities Exchange (ASX) or similar. A tendering framework (TF) flowchart model was presented by Urquhart et al. (2017) following their interviews with 18 contractors. However, given that tendering is heavily dependent upon human involvement, soft systems methodology (SSM) offers a way to rethink contractors' ITP. Information was analyzed from a base of 25 contractors interviewed overall, wherein 11 operate in the international market. Using results from the original 18 interviews with a further 7 detailed consultations it is argued that the use of SSM approach offers an alternative way of presenting a TF model. The proposed approach builds upon Checkland's (2000) SSM presentation format that offers a humanistic and practical way of restructuring ITP and associated framework.

Given the need for contractors to tender for work, wherein the lowest price commonly wins (Scheepbouwer et al., 2017), the re-structured TF model offers an alternative insight into contractors' approaches to corporate governance requirements while recognizing the important role of the human aspect (Sherman et al., 1996).

A review of contractor tendering procedure research literature is provided in Section 2.1. A brief overview of SSM is discussed in Section 2.2. The use of SSM in construction industry tendering is outlined in Section 2.3. In Section 3 the adopted research methodology is described and results analyzed in Section 4. A contractor TF model based on a SSM approach is presented in Section 5. SSM studies can help make sense of complex situations (Watson, 2012), but the present study does not seek to argue how things "should" be done. Instead, this study highlights a model by which practitioners can consider ITPs of a less rigid structuring. The developed model can be tested with traditionally styled tender procedure models using a Delphi panel of contractor experts (Section 6).

\section{Literature review}

\subsection{Research on contractor tendering procedures}

Research texts that cover contractors' tendering procedures as opposed to clients' procurement processes remain largely experiential in nature (e.g., Brook, 2011; Greenhalgh, 2013); these studies tend to be more focused on estimating rather than ITP governance. Laryea (2013) found 29 papers that deal with contractors' tendering procedures out of over 1300 papers published in six leading construction management journals between 1983 and 2012. Many of these papers focused on clientcontractor interactions, whereas others looked at modeling of tender markup and pricing techniques. Betts' (1990) series of flow diagrams are related to preparing prices and compiling subsequent tender submissions to clients rather than governance and review processes; Arslan et al.'s (2006) tender flow diagrams focused on incorporating etechnology into pricing steps and managing subcontractor pricing. Other tender flow diagram-related research included de Neufville and King's (1991) investigation into risk and contractors' need for work, and Cagno et al.'s (2001) examination of the probability of winning with estimated costs.

Laryea and Hughes (2008) reviewed risk and associated tender review steps (based on interviews with five contractors); Laryea and Hughes (2009) investigated the commercial review of contract terms by contractors and identified that commercial considerations meant that contractors priced risk primarily through contractual mechanisms (Laryea and Hughes, 2011). These investigations were based on embedment observations with two UK contractors. With contractors' tendering steps including tender launch, mid-tender, and finalization review meetings, Laryea (2013) found that contractors could spend 6\% to $9 \%$ of their total tender period in review meetings. Urquhart and Whyte (2017) undertook content analysis of tender research published in 27 journals between 2010 and 2016 and found that contractor ITP research remained a low-focus area. Following a series of semi-structured interviews with 20 civil contractors, they found that efficient ITP was one of contractors' three key tendering research desires.

By focusing on this identified need and gap, Urquhart et al. (2017) examined details of contractors' ITP and how they addressed increasing corporate governance requirements placed on companies through legislation, market expectations, and company practice (SAI, 2003; ASX, 2014; BEIS, 2017). Increasing procedural complexity meant many contractors were spending more than $10 \%$ (some over 15\%) of their tender period hours associated with internal tender review processes (Urquhart et al., 2017). These review requirements often included separate negotiations with offline internal legal, commercial, finance, and risk departments, which may not have been as directly invested in the tender outcome. A common characteristic of company culture is the belief of functional departments that they are the center of the business while operating in "silos" (Sherman et al., 1996). Some contractors mentioned that their key tender focus was risk mitigation to avoid winning a potential loss-making project (Urquhart et al., 2017).

Urquhart et al. (2017) proposed an ITP qualitative flowchart, running from prospect identification to contract award; that showed the numerous, often multi-level management, review steps or "gates" contractors undertook to secure work. Their framework diagram (adapted version shown in Fig. 1) is reflective of what Checkland (2000) called the apparent certainty conveyed by straight arrows and rectangular boxes typical of work in science and engineering, rather than a more humanistic natural 


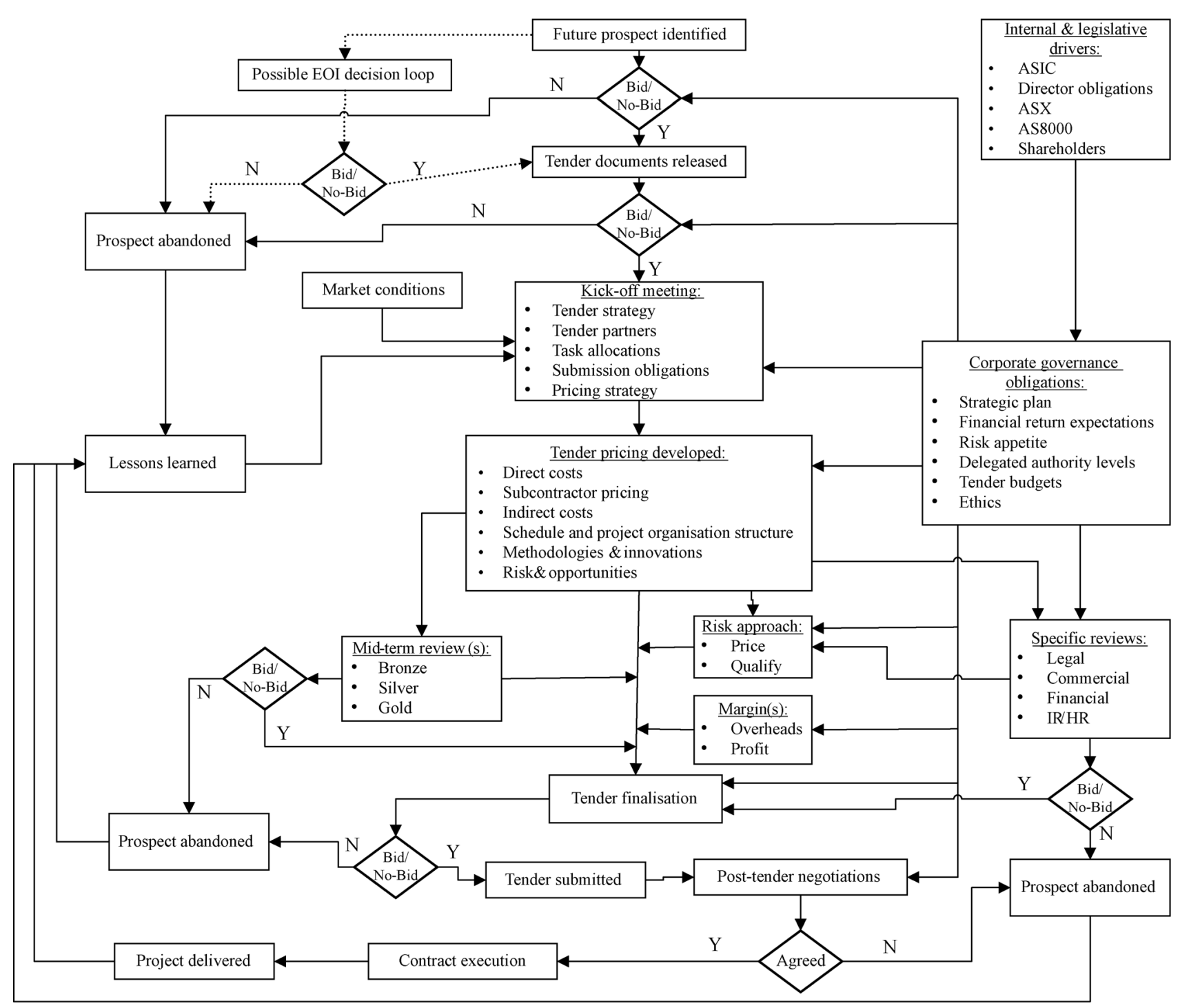

Fig. 1 Flowchart model of tendering procedure of contractors (adapted from Urquhart et al., 2017)

style with "soft" shapes and curved arrows that comes from a SSM approach. The "hard" presentation approach was consistent with how the interviewed contractors presented their written procedures to meet ISO 9001: 2008 (SAL, 2008) and QMS certification requirements. Reference to ISO 9001: 2008, instead of ISO 9001: 2015, is used in this study as there are the specific references to "tender" in the 1994, 2000, and 2008 code versions whereas the 2015 version has no direct reference to "tender" and instead adopts a wider risk assessment basis. Comments by several contractors during the interviews (Section 5) indicate that some ISO 9001 certification auditors sought to influence ITP content because of what the auditor had seen when recertifying larger contractors.

Quality procedures are required to address nonconformances. This requirement leads to the following question: Does an ITP that does not lead to a tender win (or at least a win at industry accepted rates or company expected frequencies) constitute a non-conformance or is it just a fact of contracting life? Yean Yng Ling and Liu (2005) considered a contractor reasonably successful if it won one in every five tenders submitted. Clients, or construction company shareholders, would not accept one in five success rates on construction activities like steel supply or asphalt placement performance. Therefore, developing ITPs on the same basis as other construction procedures may create false expectations from stakeholders. To paraphrase Checkland (2000), poor results from methodologies used by humans cannot be easily attributed to either incompetent use of the procedure or a poor methodology.

\subsection{SSM: A methodology, not a method}

SSM was developed 40 years ago (Watson, 2012) to address the inability of systems engineering to cope with 
the complexities of human affairs and management situations (Checkland, 2000). SSM has been used to address ill-structured problems, such as value management, from the sociological perspective while emphasizing learning and human content system models (Fellows and Liu, 2008). Checkland (2000) stressed that SSM is a methodology (or principles of method) rather than a single method (or fixed step-by-step process) and must be tailored to what the user considers appropriate to that particular situation (Watson, 2012).

While SSM has proven useful in situations rather than in methodology orientated studies it is open to new applications (Checkland, 2010). Hence, SSM may prove useful in rethinking suitable frameworks if applied to a wider industry problem of contractors' ITP instead of examining single organizations. The key consensus challenge of multiple personalities within an industry of diverse company cultures and business objectives continues to exist. Tendering and estimating teams with noble intentions are humans who are following their respective company's ITP; hence, they have different world views (e.g., company's expectations of ITP, individual business unit situations, client, markets in which they operate). Their views influence their interpretations of such requirements. These world views are not fixed and change over time. Each tendering event involves humans who aim to take deliberate, well-intended and thought-about purposeful actions (Checkland, 2010). Thus, ITPs seem ideally placed for consideration in a SSM context.

The originally developed SSM was presented as a sevenstep approach with iterations between steps (Checkland, 2000):

(1) Analysis of an unstructured problem situation (often using rich picture diagrams);

(2) Root definition of relevant systems to express a notional human activity system whose boundary might coincide with real-world organizational boundaries;

(3) Conceptualization of certain selected features of the problem;

(4) Comparison and definition of changes;

(5) Selection of changes to be implemented;

(6) Design of changes to be made;

(7) Implementation and appraisal.

In earlier methodology descriptions, Steps 1, 2, 5, 6, and

7 were undertaken in a "real-world" context, whereas Steps 3 and 4 could be driven by "systems thinking," but the sequence should not be imposed upon the practitioner (Checkland, 1999). Instead of being used as a recipe, SSM was considered more effective as a framework to place purposeful activity during a systems study to stimulate debate and capture the views of participants (Maqsood et al., 2006). Checkland and Tsouvalis (1997) and Checkland (2000) argued for simplification to a fourstage process and the removal of the "systems-world" and "real-world" demarcations that involved:

(1) Finding out about a problem situation, including social and political aspects;

(2) Formulating relevant purposeful conceptual activity models;

(3) Debating the situation, using the models, to (a) achieve desirable and (culturally) feasible changes and (b) accommodate conflicting interests so actions to improve can be taken; and

(4) Taking action to bring about improvement.

Many practitioners still utilize the seven-step process, but the four-stage approach is adopted in the present study.

The formation of the real world system for modeling is often written in the form of "a system to do P, by Q, in order to achieve R" and is typically facilitated by CATWOE analysis (Checkland and Scholes, 1990); this pneumonic means:

Customers - who benefit or suffer from the named system output;

Actors - who perform transformation tasks;

Transformation - conversion of inputs to outputs;

Worldview - the bigger picture that makes $\mathbf{T}$ meaningful;

Owners - those with the power to stop T; and

Environment - limitations/constraints that could affect solution and success.

The success or failure of these transformations are typically monitored and controlled, originally, by three elements ("3Es") (Checkland et al., 1990):

- E1 (Efficacy) - producing expected outputs;

- E2 (Efficiency) - not using resources extravagantly; and

- E3 (Effectiveness) - meeting the "owner""s goals and aspirations;

Subsequently Checkland and Tsouvalis (1997) proposed an additional "2Es" could also be applied:

- E4 (Ethically) - transformation should be morally correct; and

- E5 (Elegance) - aesthetically pleasing transformation.

A feature of SSM presentations is the use of handwritten and curved shapes designed to indicate a less rigid humanistic approach to a process rather than the apparent certainty conveyed by straight lines and arrows, right angles, and rectangular boxes (Checkland, 2000) shown in contractors' ITP flowcharts. The natural curved presentation style was intended to indicate that working models undergo continuous development rather than definitive once-and-for-all statements (Checkland, 2000). The methodology can be used to deal with the content of a problematical situation or the process of dealing with that content (Checkland and Winter, 2006); this process results in the development of a relevant system rather than a correct general system (Maqsood et al., 2006). According to Mochtar and Arditi (2001), the highly unstructured tendering approaches of contractors make them difficult to model. Using SSM in ITP research will not result in a onesize-fits-all model, but it may offer a framework that contractors can adapt to address their specific needs. 


\subsection{SSM use in construction and tendering research}

Some construction and construction management researchers have used SSM as a way to address the uncertainties and variables that make structuring construction research problematic (Li and Love, 1998). Sutrisna and Barrett (2007) demonstrated how rich picture diagrams that originated from SSM information could be combined with grounded theory to model the storylines of construction project case studies. Lean construction opportunities within a large Hong Kong contractor's supply chain management were investigated using SSM by Davis et al. (2010). Farag et al. (2016) used SSM to deliver a conceptual framework to organize social value delivery processes across all phases of construction projects as required by the Generic Design and Construction Process Protocol development. SSM has been used to undertake procurement strategy risk assessments, albeit from a client's perspective (Smith et al., 2006). It should now be a short step to applying SSM to the wider ITP processes for contractors.

SSM use in contractor tendering research is limited. A search conducted in January 20, 2018 for $<$ Soft Systems Methodology $>A N D<$ Tender* OR Bid* $>$ in article title, abstract, or keywords in the Scopus, Web of Science, and Science Direct databases produced only two relevant references. Arowosafe et al. (2015) used SSM on data obtained from 49 questionnaire responses and a literature review to develop a conceptual model around competitive bidding processes in public procurement in Nigeria. The closest to modeling contractors' ITPs using SSM was Erkoyuncu et al.'s (2014) use of a seven-step SSM to develop an uncertainty-driven framework to assist with the management of cost estimate risk associated with bidding engineering services in the defense industry. Document sharing supported their approach with 19 semi-structured interviews obtained from four organizations and three case studies.

Expanding the database search to $<$ Tender* OR Bid* > in all fields produced a few more relevant papers. Yeo and Tiong (2000) investigated "management of difference" in risk reduction strategies for negotiating, winning, and managing build-operate-transfer concessions. They adopted SSM as a framework that places emphasis on separating reality from concepts and has the flexibility to bridge knowledge and perception differences, both systemically and culturally, via a debate before realworld actions were contemplated. A strong correlation was found between risk reduction and high competence of the human actors at individual, team, and organizational levels. This finding is consistent with the contractor interview responses in the present study (Section 4). Liu et al. (2012) used SSM to develop a strategic performance management system for a high-tech Chinese company, but they did not follow traditional SSM conceptual models because they were not developed in a diagram format (i.e., no rich picture diagrams). Instead, their models were task sets based on the concepts of innovation and optimization of SSM guided by long-term objectives approved by the company's executives after rounds of discussions.

Maqsood et al.'s (2006) work is not strictly ITP-related, but it is relevant as SSM was used as a study tool to assess a leading Australian construction company's procedures in collecting and using historical project data for input into tenders. Contractors' procedures around capturing project histories and their tender teams' effective use of that information in later tenders have proven to be a challenge for various reasons (Shokri-Ghasabeh and Chileshe, 2014). Maqsood et al.'s (2006) use of SSM facilitated the development of six actions that their contractor could adopt to improve its knowledge management of project histories for input into tenders.

Checkland (2000) raised the increased flexibility of the four-stage SSM process, but most of the researchers followed the seven-step process. The re-evaluation of the TF presented in Section 5 utilizes the four-stage process.

\section{Research methodology: Semi-structured interviews}

A series of semi-structured interviews was undertaken with 25 purposefully selected contractors within a wider research program into the efficiency and effectiveness of contractors' ITP. Purposeful selection targeted a crosssection of high-profile publicly owned ("Public") and privately owned ("Private") contractors with a range of annual turnovers. Of the 30 contractors approached, 25 agreed to be interviewed. The demographic split of the interviewed contractors is summarized in Table 1. Most of the respondents have a predominantly civil engineering construction focus. Tier 1 (T1), Tier 2 (T2), and Tier 3 (T3) annual turnover size classification was adopted in this study and is roughly consistent with the terminology that contractors use to describe their competitors.

The T1 high end range of over AU\$10 billion has been left open to avoid possible identification, other than to note some of these contractors are among the largest operating

Table 1 Number and demographics of contractors interviewed by ownership and turnover

\begin{tabular}{lccc}
\hline Tier / Annual Turnover & Overall Numbers & Public Ownership & Private Ownership \\
\hline T1 - AU \$1b-10+b & $6(24 \%)$ & $5(20 \%)$ & $1(4 \%)$ \\
T2 - AU \$100m-\$1b & $11(44 \%)$ & $4(16 \%)$ & $7(28 \%)$ \\
T3-<AU\$100m & $8(32 \%)$ & $4(16 \%)$ & $4(16 \%)$ \\
\hline
\end{tabular}


in Australia. To maintain anonymity and confidentiality, given enquiries involved the sensitive issue of ITP, each contractor was assigned a randomly selected three-letter acronym for identification purposes. Twenty-four of the 25 selected contractors are based in Australia, four of them are subsidiaries of international contractors, and a further seven operate overseas and within Australia. Hence, the selection mix provided a good basis for international extrapolation of the findings.

Semi-structured interviews provided opportunities to ask more general questions and develop rapport before asking deeper probing questions for extra information (Fellow and Liu, 2008); this process is considered essential when asking about ITP. The interviews are primarily a qualitative research approach, but they also sought quantitative data as they also served as a pilot test for a planned wider industry survey. Questions informed by and developed from a detailed literature review, including previous access to contractors' ITP extracts, consisted of three parts.

Part 1 - This part sought company and individual interviewee demographics. Seven contractors secured $60 \%$ to $80 \%$ of their turnover by competitive tender, whereas the remaining 18 contractors secured $80 \%$ to $100 \%$. Interviewees who represented their individual companies had 10 to 40 (average 23.8) years of experience in the construction industry. Positions held ranged from Estimating Manager/Pre-Contracts Manager to Managing Director/Chief Executive Officer level and can be considered regularly involved in tender review procedures.

Part 2 - This part consisted of various "check list" and "rating scale" questions (Leedy and Ormrod, 2013) around tender prospect selection methods, risk assessment methods, tender review structures, and markup determination processes (actual values were not asked). This section included a series of seven-point Likert rating questions on the interviewee's opinions about the company's ITP and provided an opportunity to triangulate Part 3 responses.

Part 3 - This part involved an open discussion seeking contractor opinions on and approaches to their ITP including strengths and weaknesses, procedural steps (from prospect identification to contract award), use of electronic and paper approval forms, effectiveness and efficiency of review processes (including management levels involved), integration of previous tender and project lessons into current tenders, and competitor assessments.

The interviews lasted for 1.5 to $2.5 \mathrm{~h}$ were conducted between November 2016 and January 2018. They were held in accordance with the host institution's ethics requirements. Nineteen contractors agreed to the detailed discussion (Part 3) being audio recorded, whereas only handwritten notes could be taken for the remaining six. Typed interview transcripts, or notes as applicable, were returned to the individual participants to review, adjust if necessary, and approve. To facilitate additional detailed analysis on a strictly confidential basis, 11 contractors provided redacted extracts from their tender procedures and/or forms as exemplars. NVivo 11 and content analysis were used to categorize information extracted from the approved interview transcripts and ITP extracts into progressively developed themes (Love et al., 2012; Krippendorff, 2013).

To facilitate consistency with the SSM context objectives of this paper, the focus presented below relates to the humanistic view of and approach to contractors' ITP.

\section{Interview findings}

\subsection{Contractors' views of their tendering procedures}

Part 2 of the interviews asked the contractors to rate their views on their tendering procedures on a Likert rating scale of 1 to 7 (where " 1 " represents "strongly disagree," "4" represents "neutral" and "7" represents "strongly agree"). Responses by ownership and turnover demographic are summarized in Table 2. The wide range in scores for each question was not unexpected, given the different stages of contractor ITP redevelopment occurring within the individual companies, and suggests diversity in opinions. The variation in ratings was consistent with the more detailed responses obtained in the Part 3 discussions.

Given the low number of interviewed contractors within some demographics and the wide range in rating, only basic descriptive statistics (averages) were used in Table 2 and were relevant to apply in the study. However, the values facilitate discussion on a few trends from a qualitative perspective, particularly on the differences in views between Public T1/T2 and the other contractors:

Q1 - Interviewees for the Public and Private T1s considered their procedures less "user-friendly." Responses revealed that they had more complicated ITPs, were more likely to be required to engage with other internal departments that may not have accountability for the tender result (e.g., risk committees), and were more likely to have multiple reviews sequentially involving multiple layers of management.

Q4 - In keeping with Q1 responses and reflected in Part 3 detailed discussions, Public T1s have more multiple reviews involving multiple layers of management and are subject to wider governance control issues than other contractors (e.g., ASX, 2014; BEIS, 2017).

Q5, 6 - With a nominally higher rating for Q6 than Q5 and reflected in reflected in Part 3 responses, results suggest that Public T1/T2 procedures may place a greater focus on not winning a project that could lose money than on winning the project.

Q7 - Contractors were generally neutral, but Public T1s are slightly more inclined to suggest that their ITPs did not lead to better quality tender submissions to their clients despite attention to client being required in ISO 9001 (SAL, 2008). However, given that these contractors are 
Table 2 Likert rating responses - overall and by demographics

\begin{tabular}{|c|c|c|c|c|c|c|c|c|c|}
\hline & \multirow[t]{2}{*}{ a) Rating question } & \multirow[t]{2}{*}{ b) Response Range } & \multirow[t]{2}{*}{ c) Ave } & \multicolumn{3}{|c|}{ d) Public } & \multicolumn{3}{|c|}{ e) Private } \\
\hline & & & & $\mathrm{T} 1$ & $\mathrm{~T} 2$ & $\mathrm{~T} 3$ & f) $\mathrm{T} 1$ & $\mathrm{~T} 2$ & $\mathrm{~T} 3$ \\
\hline Q1 & $\begin{array}{l}\text { The company's tender procedures and associated forms are } \\
\text { user-friendly, easily available, kept up-to-date and easily } \\
\text { grasped by people who need to use them. }\end{array}$ & $2-7$ & 5.0 & 4.6 & 5.8 & 5.5 & 4 & 5.1 & 4.5 \\
\hline Q2 & $\begin{array}{l}\text { Senior management has a good appreciation of the work } \\
\text { the tender team must undertake to comply with the } \\
\text { specified tender procedures and associated forms. }\end{array}$ & $2-7$ & 5.5 & 5.6 & 5.8 & 5.8 & 5 & 5.6 & 5.0 \\
\hline Q3 & $\begin{array}{l}\text { Personnel directly involved in tender preparation made a } \\
\text { significant contribution toward the development of the } \\
\text { tender procedures and forms. }\end{array}$ & 3- 7 & 5.2 & 4.6 & 4.5 & 5.0 & 3 & 6.0 & 5.8 \\
\hline Q4 & $\begin{array}{l}\text { The various tender review stages/steps lead to significant } \\
\text { duplication of work, often with the same information } \\
\text { having to be presented in another way for a higher level of } \\
\text { management, rather than consistently applied right up to } \\
\text { CEO/MD level. }\end{array}$ & $1-7$ & 3.3 & 5.8 & 2.3 & 2.8 & 3 & 3.1 & 2.0 \\
\hline Q5 & $\begin{array}{l}\text { The key purpose of our tender procedures is to help the } \\
\text { company win a profitable project. }\end{array}$ & $2-7$ & 5.6 & 5.0 & 5.5 & 5.5 & 6 & 5.9 & 5.8 \\
\hline Q6 & $\begin{array}{l}\text { The key purpose of our tender procedures is to make sure } \\
\text { the company does not win a money-losing project. }\end{array}$ & $2-7$ & 5.4 & 5.4 & 5.8 & 5.3 & 4 & 5.9 & 4.8 \\
\hline Q7 & $\begin{array}{l}\text { Our tender procedures and forms do not lead to an } \\
\text { improvement in the quality of the tender submitted to the } \\
\text { client. }\end{array}$ & $1-6$ & 3.8 & 4.6 & 3.0 & 4.0 & 3 & 3.3 & 4.3 \\
\hline Q8 & $\begin{array}{l}\text { Our tender procedures are not adjusted to cater for } \\
\text { tendering projects of different project delivery methods. }\end{array}$ & $1-7$ & 4.0 & 4.4 & 4.8 & 5.0 & 6 & 3.3 & 2.3 \\
\hline Q9 & $\begin{array}{l}\text { The tender procedures are not adjustable to cater for } \\
\text { tendering projects to specific clients, even when such } \\
\text { clients have a history of tender requirements and no } \\
\text { flexibility in accepting qualifications to proposed contract } \\
\text { terms (e.g., the state government requirement for a fully } \\
\text { conforming bid). }\end{array}$ & $1-7$ & 3.9 & 4.0 & 3.8 & 4.5 & 3 & 4.1 & 3.0 \\
\hline
\end{tabular}

Notes: a) The underlined "not" in Q6 to 9 was added for convenience in this paper; b) Range of interviewee responses to the Likert scale item; c) Average of response ratings from all 25 contractors; d) Public contractors; e) Private contractors; and f) only one response received so actual scores provided rather than an average. The response averages in bold font are analyzed below.

more likely to pursue projects where clients include a shortlisting phase, the higher client focus may occur at the expression of interest step.

Q8, 9 - The near neutral average response positions suggests increased diversity in how contractors approached their tendering procedures (reflected in the Part 3 discussions), despite the range in rating responses.

These responses help inform the human approach to tendering and were reinforced by the contractors' detailed responses to questions in Part 3.

\subsection{Trends in contractor interview comments}

Two common trends were identified, regardless of the nature of the contractors' ITP.

1) ITPs could always be improved. Six contractors were in the process of modifying their ITPs; 12 had modified theirs within the last three years; and the remaining seven had not modified their ITPs in the last five years. Although one contractor noted a need to rewrite them.

2) ITPs were heavily dependent on the quality of the people involved in tenders and reviews. Contractors commented that no procedure could counteract the position where if the personnel involved were not sufficiently capable, then the end result (either winning the tender or the subsequent project's profit outcome) was less likely to be favorable.

Other findings relevant to the aims of this study are as follows.

- Most of the interviewees' verbal response tones indicated a level of frustration with their ITP mechanics, if not overtly stated, especially where one set of procedures applied to different project delivery methods, clients, and project values. A Public T3 advised "for procedures, it is always the same problem: one size has to fit all when you write them," which supports the merits of looking at a different ITP structure along the SSM line.

- Several contractors of varying demographics indicated that their company's purpose was to make profits and not to win tenders. They recognized that such a view created conflict for business development and tendering teams. Their ITP focus was more of "avoid winning loss losing 
projects." They claimed that having less money losing projects validated their ITP changes. However, some added that not making money can also lead to questions on the effectiveness of the ITP. One T1 indicated that they still occasionally win a "dog project" (a colloquialism for a negatively performing project) (Urquhart et al., 2017), despite having all these procedures in place.

- With engineering and construction being such an evidenced-based industry, it was of little surprise that statements regarding trusting people to do tender reviews rather than having signed off evidence only came from a Private T2 and T3. However, $50 \%$ of the 12 contractors who stated that it was people rather than procedures that made the difference in tender reviews were Public (four $\mathrm{T} 1 \mathrm{~s}$ and two T2s). Hence, the contractors with more governance constrained ITPs were still likely to recognize that it was individual people and not the system that made the difference. Thus, questioning what increased governance really achieves.

Content analysis of Parts 2 and 3 responses and provided redacted ITP extracts identified that a multi-approval "gate" process with multi-management level involvement each time was commonly adopted by contractors as ITP governance. The approach is modeled in Fig. 2. The commonly adopted five gates are shown, but some contractors use up to seven. The number of steps up through management levels at each gate depends on the applicable delegation of authority (DoA) levels typically determined by perceived risk levels with the project contract value being the most common determinant. Other factors also determine the level of management escalation for approval, but they are not within the scope of this study.
The model recognizes that decisions are often supported by various offline support review departments. The contractors' multigate approach to seeking approval to tender at the various stages in a project procurement life cycle is not inconsistent with the Stage-Gate ${ }^{\circledR}$ project development approach, which has been modified by companies in pursuit of increased governance and made overly bureaucratic (Cooper, 2014). In other words, involvement of high layers/levels of management still requires a human element for success. The importance of the human factor in the success of risk management, a component of tendering, is recognized in such texts as Smith et al. (2006).

Further findings from the interviews have been incorporated into the SSM-based approach discussion in Section 5.

\section{Discussion: Rethinking the TF in a SSM context}

By teasing out information, which is an approach promoted by Checkland (2000), from the 25 semistructured interviews and provided procedure extracts through content analysis, Urquhart et al.'s (2017) proposed TF was reassessed within a SSM context. The less rigid procedural context framework presented below (Fig. 3) offers a basis for industry practitioners to reconsider their respective ITP formats. The suitability of the SSM context approach will be tested along with several other framework formats in a planned Delphi panel stage with selected industry experts (Section 6). An ITP framework (not an estimating procedure/process) is discussed.

The proposed TF follows Checkland's (2000) SSM

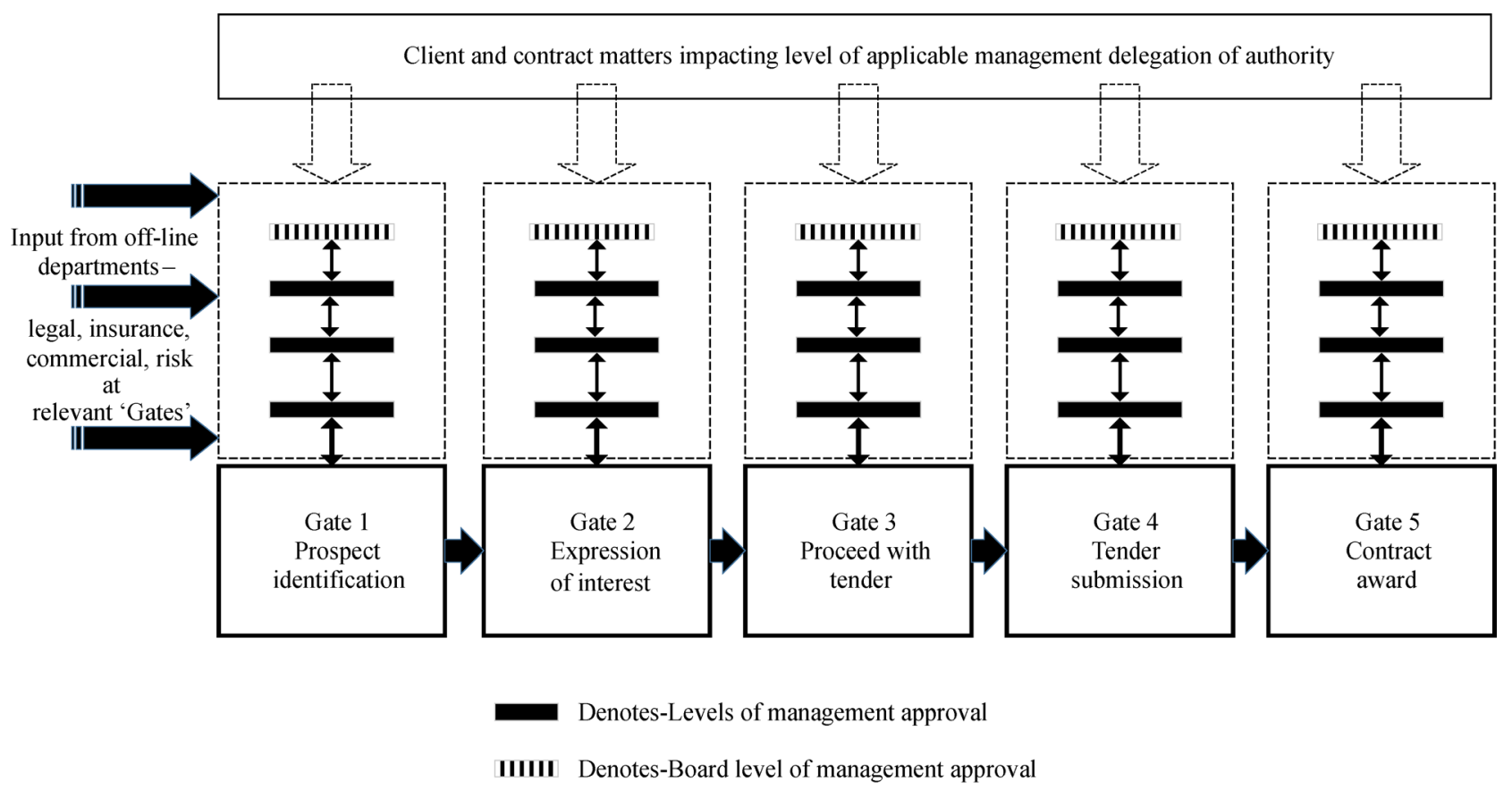

Fig. 2 Model of the corporate approval steps during tender stages, as applied by many contractors 
four-stage methodology:

1) - Find out about a problem situation: Tendering is a constantly moving target with different clients; clients with changing demands (tender-by-tender); market conditions; estimating teams; and contractor entities and corporate requirements. Similar to Liu et al. (2012), the use of process flowcharts and interview transcript data was applied instead of drawing rich picture diagrams.

2) - Formulate relevant purposeful conceptual activity models: Various framework elements can be added, including contract risk appetites; use of different tender review concepts of start-up, mid-tender, and final reviews; varying corporate review and approval parameters (including DoA); and involvement of offline internal departments. 3) - Debate the situation using the models: This approach was undertaken at one level by the researchers reviewing contractor responses. The researchers were not strictly "accountable participants" (Checkland, 2010), but the lead author spent 20 years managing tenders for some of Australia's largest contractors, thereby confirming realworld knowledge (Checkland, 2000). The researcher was able to engage in "debate" in the Part 3 questions. Further iterative "debate" will occur through a planned Delphi panel of industry experts. In addition, the opportunity to raise debate through this study per Scheepbouwer et al.'s (2017) approach on the lowest tender price debate is encouraged. Future debates will seek:

a) desirable and (culturally) feasible changes: e.g., balancing client and corporate contract objectives, which is a challenge with increasing use of bespoke contracts (Whyte, 2015) in Australia;

b) to accommodate conflicting interests while facilitating action to improve: the "need to win the tender" at a contractor business unit level, especially when having to compete for internal tendering resources; balancing clients' objectives on agreed contract terms with corporate risk appetites; and the need to verify governance compliance in the context of constantly changing markets. 4) - Suggest an action to bring about improvement: "Suggest" as opposed to Checkland's (2010) "take" as this proposed framework considers an industry of competitors rather than a single company. Examples from the interviews: improved lessons learned capture system and knowledge management for future tenders; tender procedures that also improve the submission to the client; and separating "tender manuals" from "tendering procedures." This process facilitates increased flexibility to modify rigid procedural aspects to separately address a contractor's high-value repeat clients, associated contract terms, and more relational based contract delivery methods.

Control and monitoring can be incorporated into an ITP by considering:

- E1 (Efficacy): the procedure enables tenders to meet client and corporate objectives at a realistic frequency, while not being confused with a production control-type QA procedural outcome;
- E2 (Efficiency): spending time only on tenders that have a realistic chance of meeting the specific bid strategy objectives (recognizing that an objective may not be winning the tender);

- E3 (Effectiveness): several "owners" may apply, refer CATWOE discussion below;

- E4 (Ethically): tendering in a manner that meets ethical and legal expectations; and

- E5 (Elegance): externally, an attractive tender for the client (form and substance); and internally, an ITP that tender teams will want to use (e.g., reduce the growing number of sub-procedures and reporting forms, or separating tender procedures from manuals).

The criteria by which the holistic performance of the system will be judged will differ for each contractor and change with time and market conditions. Some reasons why contractors need to win tenders are to keep staff employed, to make profits for shareholders, to move into new markets or new clients, and to exclude competitors from gaining access to clients or markets (Skitmore and Smyth, 2007). Larger contractors with centralized systems recognize that such criteria may differ across work type and geographically-based business units.

As a process of rethinking a TF, and as a step in the framework methodology itself, the CATWOE components (above) are reconsidered in a contractor tendering environment context:

Customers - clients procuring construction work through a tender process and contractor's shareholders who expect sustained growth and profits;

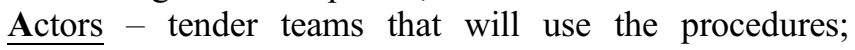
contractor's offline departments and risk committees; line management to the extent permitted by DoA; and directors facing legal governance obligations for their companies; Transformation - changes might include: structural (interactions with commercial and legal departments, and boards); procedural (reduce or realign multiple approval set "gates," i.e., simplify the process outlined in Fig. 2); outlook/attitude (i.e., understanding of/empathy with the amount of time spent in reviews); success expectations; and willingness to try the change;

Worldview - more efficient ITP reduce tender costs thus benefiting clients with reduced infrastructure costs; and shareholders with increased profits. Both are likely to be better for society;

Owners - will involve a number of Actors depending on the extent to which a contractor involves its tendering teams in procedure development (interviews suggest a wide approach already applies); line management DoA; and most importantly, the ownership structure and whether the company is Public or Private. Sole owners may dictate more, but large Public companies face more stringent corporate governance expectations; and

Environment - changing market and business cycles, especially during peaks of booms and troughs of recessionary times. If these changes are not reflected in written 
procedures, they will be considered during tender reviews. As several contractors advised, losing money on several projects in a row will cause ITP to become more stringent.

Two avenues were identified while using NVivo 11 and content analysis to review the semi-structured interview data in the context of the SSM approach:

1) SSM provides a useful enquiring/learning cycle means for how an ITP framework can be more fully investigated in a construction industry sense and subsequently redeveloped. The approach is illustrated in Fig. 3. The alternative SSM context model continues to recognize internal and legislative factors driving corporate governance that influence the "bid/no-bid" decisions and specialist department involvement at key tender reviews. Separation of "real-world involvement" and "systems thinking" remains to mirror governance and ISO 9001 (SAL, 2008) certification verification demands. However, the demarcation is less distinctive and is not shown in this model.

2) The SSM based presentation model (Fig. 3) offers an alternative way for a contractor to consider and, if appropriate, present its project pursuit ITP in a more humanistic way instead of the traditional rectangular boxes and straight lines commonly adopted and suggestive of ISO 9001 (SAL, 2008) procedures with associated expected repeatable tender outcomes. This approach has been superimposed on Fig. 3 with extra specific tender text shown in brackets (different font). CATWOE, E1 to E5, and, if necessary, PQR need not occur at the same step(s) for root definition because adjustments commonly occur during a full project pursuit cycle.

\section{Conclusions and further research}

Construction contractors' ITPs are becoming increasingly complex in their nature to address increased corporate governance demands. As part of a wider study into the effectiveness and efficiency of such procedures, a series of semi-structured interviews were undertaken with 25 contractors purposely selected to cover a range of public and private ownership structures and annual turnover sizes. Addressing a gap identified in the research (Urquhart and

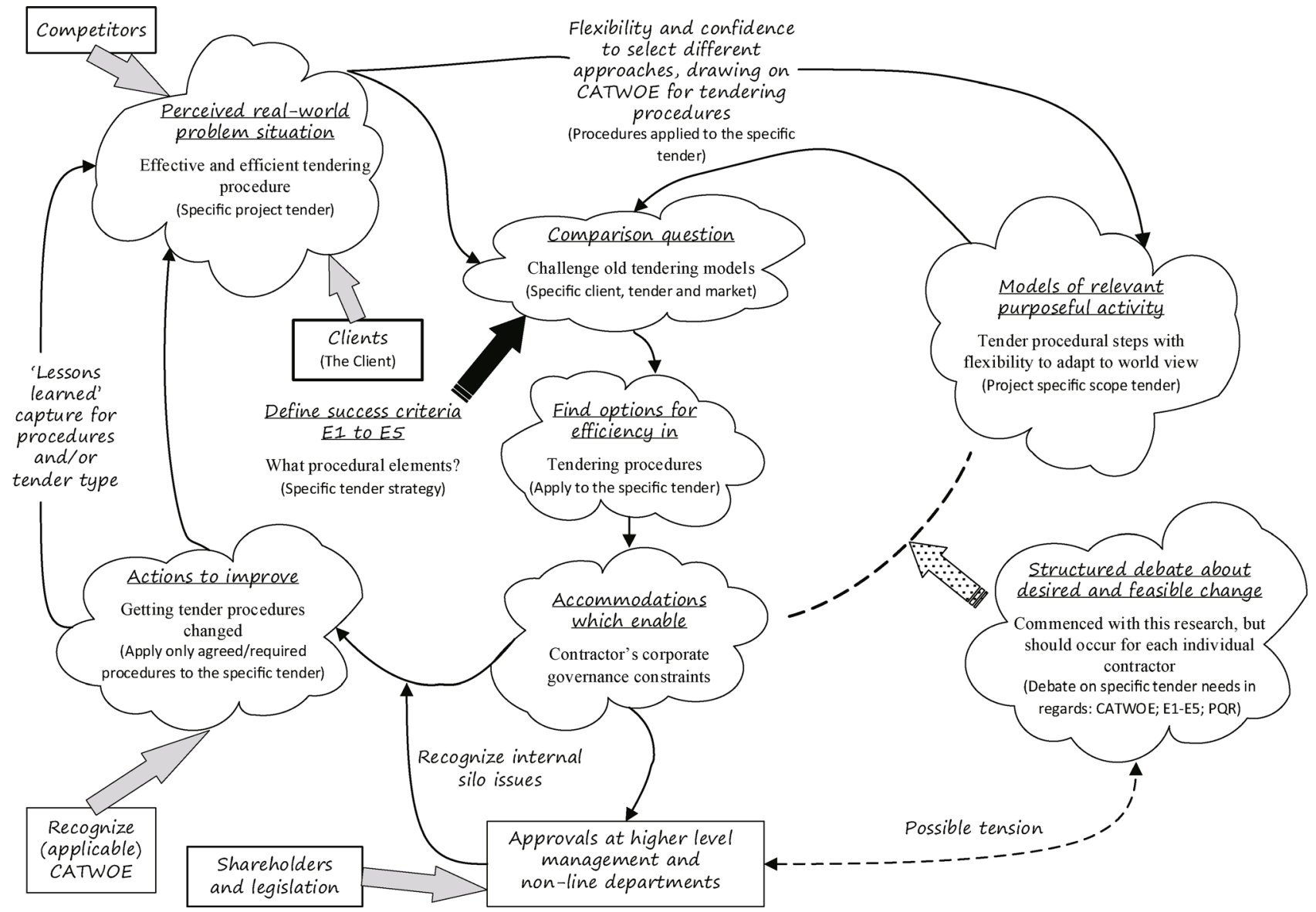

Fig. 3 Tendering procedure flowchart framework development in a SSM context. Incorporated within this model is an example (specific text shown in brackets) of how the same SSM format graphic could also be adopted by a contractor to present its ITP in a more humanistic and flexible framework (adapted from Checkland and Scholes (1990, Fig. 10.8) and Checkland (2000, Fig. A1), then modified to include various ITP steps drawn from the semi-structured interviews) 
Whyte, 2017), content analysis of the interview data and received redacted tender procedure extracts were used to develop and propose a TF flowchart model that embraces SSM.

The analysis of the data and subsequent presentation of findings in a SSM context of a human focused approach provided an alternative way of assessing the interviewobtained data. It also offered a way wherein a TF can be more fully investigated within the construction industry and subsequently developed (Fig. 3). After expanding on the SSM's "debate" process, the next step in the wider research program (already currently ongoing) is to evaluate and test this SSM-aligned flowchart model via a Delphi panel of construction industry experts. This approach will provide a vehicle for possible industry change and lead to an improvement in tendering efficiency. Consensus across different businesses and business drivers is not the goal. The aim is to facilitate consideration of more efficient tendering processes that lead toward reduced tendering and overall infrastructure delivery costs. Enhancement may remain an aim though Checkland (2000) cautions that any methodology such as SSM cannot lead to an "improvement."

A commonly adopted SSM presentation structure offers an alternative way for contractors to present their own ITP frameworks in a more humanistic and flexible manner. The SSM curved soft shapes approach format may be a viable alternative framework for some contractors, rather than the somewhat visually rigid "exact answer" approach suggested by the straight-line arrows and rectangular boxes (Checkland, 2000) common in production-type QA procedures. The framework in Fig. 3 should only be considered an option because SSM models are not definitively valid or invalid but rather technically defensible or otherwise (Checkland and Scholes, 1990) and may either be a relevant system (Maqsood et al., 2006) or not. This (re-) thinking of a contractor's tendering processes in an SSM context is recognized not as a "one-size-fits-all" solution but rather one that contractors may utilize to adapt respective concerns toward efficiency and effectiveness gains in tendering procedures.

Acknowledgements The authors acknowledge the contribution of an Australian Government Research Training Program Scholarship. They also acknowledge the participation of the 25 (anonymous) construction contractors interviewed for this study and the anonymous reviewers for their valuable comments that helped improve this manuscript.

\section{References}

Arowosafe O, Ceranic B, Dean A M (2015). A sustainable infrastructure delivery model: Value added strategy in the Nigerian construction industry. In: Proceedings of 31st Annual ARCOM Conference. Lincoln: 1229-1238

Arslan G, Tuncan M, Birgonul M T, Dikmen I (2006). E-bidding proposal preparation system for construction projects. Building and Environment, 41(10): 1406-1413

ASX (Australian Securities Exchange) Corporate Governance Council (2014). Corporate governance principles and recommendations (3rd Edition). http://www.asx.com.au/documents/asx-compliance/cgcprinciples-and-recommendations-3rd-edn.pdf, 2015-10-24

BEIS (Dept for Business, Energy \& Industrial Strategy) (2017). Corporate governance reform: The Government response to the green paper consultation. https://www.gov.uk/government/uploads/ system/uploads/attachment_data/file/640631/corporate-governancereform-government-response.pdf, 2018-3-1

Betts M (1990). Methods and data used by large building contractors in preparing tenders. Construction Management and Economics, 8(4): 399-414

Brook M (2011). Estimating and Tendering for Construction Work. London: Spon Press

Cagno E, Caron F, Perego A (2001). Multi-criteria assessment of the probability of winning in the competitive bidding process. International Journal of Project Management, 19(6): 313-324

Checkland P (1999). Systems Thinking, Systems Practice. Chichester: John Wiley \& Sons

Checkland P (2000). Soft systems methodology: A thirty year retrospective. Systems Research and Behavioral Science, 17(S1 SUPPL): S11-S58

Checkland P (2010). Researching real-life: Reflections on 30 years of action research. Systems Research and Behavioral Science, 27(2): 129-132

Checkland P, Forbes P, Martin S (1990). Techniques in soft systems practice part 3: monitoring and control in conceptual models and evaluation studies. Journal of Applied Systems Analysis, 17: 29-37

Checkland P, Scholes J (1990). Soft Systems Methodology in Action. Chichester: John Wiley \& Sons

Checkland P, Tsouvalis C (1997). Reflecting on SSM: The link between root definitions and conceptual models. Systems Research and Behavioral Science, 14(3): 153-168

Checkland P, Winter M (2006). Process and content: Two ways of using SSM. Journal of the Operational Research Society, 57(12): 14351441

Cooper R G (2014). What's next? After stage-gate. Research Technology Management, 57(1): 20-31

Davis L, Miles M, Riley M, Pan W (2010). Developing lean supply in construction. In: Proceedings of 26th Annual ARCOM Conference. Leeds: 705-713

de Neufville R, King D (1991). Risk and need-for-work premiums in contractor bidding. Journal of Construction Engineering and Management, 117(4): 659-673

Erkoyuncu J A, Roy R, Shehab E, Kutsch E (2014). An innovative uncertainty management framework to support contracting for product-service availability. Journal of Service Management, 25(5): 603-638

Farag F, McDermott P, Huelin C A (2016). The development of an activity zone conceptual framework to improve social value implementation in construction projects using human activity systems. In: Proceedings of the 32nd Annual ARCOM Conference. Manchester, 2: 975-984

Fellows R, Liu A (2008). Research Methods for Construction. 
Chichester: Wiley-Blackwell

Greenhalgh B (2013). Introduction to Estimating for Construction. London: Routledge

Krippendorff K (2013). Content Analysis: An Introduction to Its Methodology. Thousand Oaks: Sage

Laryea S (2013). Nature of tender review meetings. Journal of Construction Engineering and Management, 139(8): 927-940

Laryea S, Hughes W (2008). How contractors price risk in bids: Theory and practice. Construction Management and Economics, 26(9): 911924

Laryea S, Hughes W (2009). Commercial reviews in the tender process of contractors. Engineering, Construction, and Architectural Management, 16(6): 558-572

Laryea S, Hughes W (2011). Risk and price in the bidding process of contractors. Journal of Construction Engineering and Management, 137(4): 248-258

Leedy P D, Ormrod J E (2013). Practical Research Planning and Design. Upper Saddle River: Pearson Education

Li H, Love P E D (1998). Developing a theory of construction problem solving. Construction Management and Economics, 16(6): 721-727

Liu W B, Meng W, Mingers J, Tang N, Wang W (2012). Developing a performance management system using soft systems methodology: A Chinese case study. European Journal of Operational Research, 223 (2): 529-540

Love P E D, Edwards D J, Irani Z (2012). Moving beyond optimism bias and strategic misrepresentation: An explanation for social infrastructure project cost overruns. IEEE Transactions on Engineering Management, 59(4): 560-571

Maqsood T, Finegan A, Walker D (2006). Applying project histories and project learning through knowledge management in an Australian construction company. Learning Organization, 13(1): 80-95

Mochtar K, Arditi D (2001). Pricing strategy in the US construction industry. Construction Management and Economics, 19(4): 405415

SAI (Standards Australia International) (2003). AS8000:2003 Good Governance Principles. Sydney: SAI Global Limited

SAL (Standards Australia Limited) (2008). AS/NZS ISO 9001:2008, Quality management systems - Requirements. Sydney: SAI Global Limited
SAL (Standards Australia Limited) (2016) AS/NZS ISO 9001:2016 ISO9001:2015, Quality management systems — Requirements. Sydney: SAI Global Limited

Scheepbouwer E, Gransberg D D, del Puerto C L (2017). Construction engineering management culture shift: Is the lowest tender offer dead? Frontiers of Engineering Management, 4(1): 49-57

Sherman D G, Cole A J, Boardman J T (1996). Assisting cultural reform in a projects-based company using systemigrams. International Journal of Project Management, 14(1): 23-30

Shokri-Ghasabeh M, Chileshe N (2014). Knowledge management barriers to capturing lessons learned from Australian construction contractors perspective. Construction Innovation, 14(1): 108-134

Skitmore M, Smyth H (2007). Pricing construction work: A marketing viewpoint. Construction Management and Economics, 25(6): 619630

Smith N J, Merna T, Jobling P (2006). Managing Risk in Construction Projects. Oxford: Blackwell Publishing

Sutrisna M, Barrett P (2007). Applying rich picture diagrams to model case studies of construction projects. Engineering, Construction, and Architectural Management, 14(2): 164-179

Urquhart S, Whyte A (2017). Contractor tendering research: Going beyond bid/no-bid and markup models. In: Proceedings of the Institution of Civil Engineers - Management, Procurement and Law. 170(6): 255-262

Urquhart S, Whyte A, Lloyd N (2017). The development of a more efficient internal tender procedure oframework for Australian construction contractors In: Proceeding of the 33rd Annual ARCOM Conference. Cambridge, 693-702

Watson R B (2012). Suggestions for new application areas for soft systems methodology in the Information Age. Systemic Practice and Action Research, 25(5): 441-456

Whyte A (2015). Integrated Design and Cost Management for Civil Engineers. Clermont: CRC Press

Yean Yng Ling F, Liu M (2005). Factors considered by successful and profitable contractors in mark-up size decision in Singapore. Building and Environment, 40(11): 1557-1565

Yeo K T, Tiong R L K (2000). Positive management of differences for risk reduction in BOT projects. International Journal of Project Management, 18(4): 257-265 